\title{
Magnani, José Guilherme Cantor. Da periferia ao centro: trajetórias de pesquisa em Antropologia Urbana. São Paulo, Editora Terceiro \\ Nome, 2012, 349 pp.
}

Alexandre Ambiel Barros

Gil Duarte

Gabriela Liedtke Becker

(UFPR)
O mais recente livro de José Guilherme Magnani é um dos resultados da parceria entre o Núcleo de Antropologia Urbana (NAU) da USP, coordenado pelo próprio professor, e a Editora Terceiro Nome. Publicado na coleção Antropologia Hoje, em 2012, o trabalho é fruto da tese de livre docência do autor, defendida em dezembro do ano anterior.

Em linhas gerais, o livro consiste num balanço crítico de sua carreira e de um tipo de antropologia que floresceu concomitante a ela. A obra estrutura-se em três partes: na primeira, Linhagens e Trajetórias, o autor reivindica filiação teórica a uma linhagem intelectual específica e inovadora, iniciada em São Paulo, que se delineou basicamente a partir dos estudos de Eunice Durham e Ruth Cardoso, sua orientadora. A segunda parte, Três Pesquisas, apresenta uma sequência de estudos realizados na capital paulista, conduzidos por Magnani e por alguns de seus orientandos, que ao experimentarem novos conceitos, temática s e objetos fortaleceram o campo da Antropologia Urbana. Na parte final, intitulada Etnografia Urbana, o autor dedica-se a uma série de reflexões acerca do trabalho etnográfico, nascidas no decorrer de todo o percurso de constituição e consolidação deste campo de conhecimento.

Ao longo do primeiro capítulo do livro, Magnani descreve o ambiente das Ciências Sociais na cidade de São Paulo, a partir da década de 1930, destacando como o fenômeno urbano foi interpretado neste período. De acordo com o autor, professores e orientadores, sociólogos e antropólogos, baseando-se em quadros comuns de referências teórico-metodológicas, transitavam entre as duas principais instituições de ensino e pesquisa (a Escola Livre de Sociologia e Política e a Universidade de São Paulo) assim como entre a questão urbana e a temática indígena. De modo geral, a cidade era concebida sob a insígnia da transformação e da mudança, mimetizada com os processos de modernização e urbanização. Ainda que houvesse reflexões sobre áreas urbanas, a cidade não era pensada a partir de suas dinâmicas 
próprias, mas apenas como palco sobre o qual se desdobram amplos processos sociais, como os fenômenos de "aculturação" e de "assimilação" de grupos como imigrantes e populações negras.

Ruth Cardoso e Eunice Durham, conforme explica Magnani detalhadamente no segundo capítulo, detectam a insuficiência destes conceitos e em seguida passam a construir uma trajetória própria de pesquisa. O principal desafio enfrentado pelas autoras foi encontrar uma alternativa teórico-metodológica que iluminasse os processos de urbanização e transformações estruturais a partir de uma abordagem propriamente antropológica. Porém, esta não poderia ficar restrita a particularismos: elas tentavam adotar uma perspectiva que evitasse categorias analíticas muito amplas e ao mesmo tempo limitadas - como "estrutura de classes" ou "ideologia", muito utilizadas pelos sociólogos da época - mas que, ao mesmo tempo, não se constituísse como mera descrição, carente de alguma análise sobre as mudanças e os conflitos que vinham ocorrendo na sociedade brasileira. A Antropologia, lembra Magnani, agora lida com o fato de que os grupos que sempre estudou ganharam visibilidade política por meio da emergência dos novos movimentos sociais urbanos. O migrante, o trabalhador ou o pobre passaram a ser reconhecidos enquanto moradores, alguém que não expressa sua natureza por pertencer a uma classe determinada, mas que constrói o seu mundo a partir de uma variedade de orientações sociais, que incluem as suas formas de lazer e os modos de sociabilidade construídos na periferia.

A mudança de perspectiva no olhar para o universo urbano e para quem nele vive resulta no que o autor identifica como "um alargamento do campo da Antropologia na USP, com desdobramentos em outras instituições brasileiras de docência e pesquisa" (:53). Cardoso e Durham passaram a orientar pesquisas sobre diversas temáticas, o que revelou uma vida urbana mais complexa, colocando os pesquisadores diante da necessidade de formular novas ferramentas de análise. Como afirma Magnani, era necessária a construção de "quadros de referência ad hoc, levando em conta as especificidades desses novos objetos de reflexão" (:56). A perspectiva marxista, com sua ênfase nas relações de poder e de classe, negava agência a diversos grupos subalternos. Era preciso reconhecer como estes adotavam formas próprias de lidar com situações de desigualdade, sempre considerando o caráter político de suas estratégias e ações. Para isso, os pesquisadores apoiaram-se em uma metodologia qualitativa, deixando um pouco de lado os questionários e surveys e preferindo ir a campo. Buscou-se mergulhar no cotidiano dos diversos atores e grupos e, por meio de entrevistas e observações, conhecer, de modo concreto, suas práticas, dinâmicas próprias, e seus pontos de vista.

Este alargamento de olhares e estudos descrito por Magnani lembra-nos o trabalho realizado por Alba Zaluar, orientado por Eunice Durham, concluído em 1984: "A máquina e a revolta: as organizações populares e o significado da pobreza". Em sua etnografia na Cidade de Deus, periferia do Rio de Janeiro, Zaluar entrevistou moradores, observou o cotidiano e as redes de sociabilidade do local, procurando analisar como os sujeitos pensavam e entendiam a política, o trabalho, a pobreza, entre outras categorias. Zaluar compreendeu que o trabalho, por exemplo, era moralmente exaltado a partir de uma ética do provedor. A identificação positiva do trabalho representada pela ideia do marido trabalhador, que não nega serviço, não significava, no entanto, apego a valores 
burgueses ou falta de consciência de classe, mas estava relacionada a uma moral específica, que estruturava as relações sociais naquele universo. A autora encontrou trabalhadores que enfrentavam criativa e reflexivamente a sua situação econômica; isto a fez perceber o quanto a literatura sociológica sobre classes sociais possibilitava uma reflexão muito limitada sobre os pobres urbanos: considerava-os como uma massa de trabalhadores, ora passiva, ora contestadora.

Magnani destaca alguns pressupostos anunciados pela nova abordagem que seguem presentes nas discussões do consolidado campo da Antropologia Urbana brasileira. Dentre eles, está a atenção que o pesquisador deve tomar para não permanecer amarrado a particularismos (o que o autor denominou como "tentação da aldeia") ou a generalizações; e também uma postura sensível e aberta que ele deve manter frente às novas problemáticas que surgem durante a pesquisa (:81). A trajetória do autor foi marcada por todos eles: escutar o que o campo lhe dizia e abrir-se para os resultados imprevistos, por exemplo, foi a postura tomada em sua pesquisa de doutorado, publicada em 1984 como Festa no pedaço: cultura popular e lazer na cidade.

Conforme relatado ao longo do terceiro capítulo, o autor escolheu como local de estudos bairros periféricos da cidade de São Paulo e como objeto o circo-teatro enquanto uma forma de entretenimento. As perguntas que inicialmente sustentavam a pesquisa - o circo era ou não um veículo de crítica social? - diluíram-se quando o autor, através da etnografia, conheceu o cotidiano dos bairros e dos espetáculos. Ao notar a existência de uma rede mais extensa de atividades de lazer e entretenimento, Magnani entendeu que o circo era apenas mais uma delas, e o seu conteúdo (político/contestatório ou não) não era algo tão central. Passou a observar, então, na sociabilidade local, uma série de oposições e ordenamentos relacionada às formas de entretenimento e ao espaço. Foi aí, então, que uma categoria nativa transformou-se em ferramenta conceitual: interposto entre a casa e a rua, o pedaço referiase a um espaço marcado por uma rede de relações específicas, geralmente de parentesco e vizinhança. Pertencer a ele, portanto, era algo que situava e diferenciava o sujeito frequentador, em meio a símbolos reconhecidos e compartilhados. Pedaço, então, passa a ser uma categoria que define um tipo específico de apropriação de um determinado espaço e das relações de sociabilidade que o permeiam. Ela começou a ser testada em outros contextos quando os estudos do autor, junto com os integrantes do Núcleo de Antropologia Urbana da USP, iniciaram um caminho da periferia ao centro.

De acordo com Magnani, logo de início percebeu-se que o centro de uma grande cidade, diferentemente de sua periferia, não era marcado por relações de forte proximidade, como de vizinhança e de parentesco. No entanto, por meio das etnografias iniciais, o "efeito pedaço" continuou sendo identificado (:93): em diferentes regiões do centro de São Paulo indivíduos buscavam algum local de referência para formar e cultivar laços e relações. Embora seus frequentadores não se conhecessem como nos pedaços periféricos, no centro da cidade os indivíduos também se reconheciam através de marcas, símbolos, códigos e hábitos compartilhados. Com o intuito de ampliar o olhar sobre espaços centrais e em busca de recorrências, ordenamentos e padrões, Magnani e seus orientandos optaram pela utilização de uma nova família de categorias analíticas (:93). Mancha passou a designar 
uma área mais ampla que o pedaço, que não perdesse de vista cruzamentos inesperados. Tentando pensar em fluxos e movimentos no interior das manchas e em outros espaços da metrópole, cunhou-se a categoria trajetos, que podem levar os sujeitos a transitarem e passarem de um ponto a outro por meio dos chamados pórticos. A descrição de determinada prática ou serviço ofertado em diferentes espaços, que são reconhecidas por quem os frequenta, pôde ser facilitada pela categoria circuito.

Vale destacar que, ainda neste terceiro capítulo do livro, Magnani discorre sobre como a perspectiva antropológica propicia uma mudança fundamental no entendimento do lazer e do tempo livre. Ao invés de nos contentarmos com perspectivas que de antemão procuram responder o papel que o tempo livre cumpre, (questionando qual é sua função ideológica, por exemplo) é inevitável partirmos de experiências concretas e do que os próprios atores sociais nos dizem que fazem nele. Os modos de consumi-lo e as práticas de entretenimento só podem ser devidamente entendidas se "consideradas per se" (:104), e se situadas na observação direta de relações que se estabelecem cotidianamente nos diferentes contextos.

A partir da leitura de Três pesquisas, fica claro como este esforço foi constantemente seguido em projetos e pesquisas desenvolvidas pelo NAU e orientadas pelo autor como Neoesoterismo na metrópole, Circuito de jovens e No mundo dos surdos. Apesar das evidentes diferenças entre os três temas, todas as pesquisas buscaram recorrências e particularidades à medida que objetivaram refletir acerca do que o lazer significa para os sujeitos envolvidos em cada situação. Nesses trabalhos a família de conceitos descrita acima é pensada a partir de uma rede de relações distintas daquelas das periferias de Festa no pedaço. Como são os circuitos daqueles que estão mais ou menos ligados ao movimento denominado “Nova Era"? De que maneira diferentes grupos de jovens - como os "b. boys" e "streeteiros" conhecidos por Fernanda Noronha, Renata Toledo e Paula Pires - que têm pedaços próprios se encontram nas mesmas machas de lazer? E quais seriam os pedaços de um grupo de surdos na cidade de São Paulo? Essas perguntas possibilitaram não somente o exercício de conceitos já estabelecidos como também a sua reformulação. Somam-se enquanto ferramentas de análise novos conceitos nativos, como no caso da pesquisa sobre pichadores feita por Alexandre Pereira, "point" e "quebrada".

Observar a existência de um circuito neoesotérico, por exemplo, permitiu enxergar os que nele circulavam a partir de diferentes trajetos, evitando pensá-los como imersos em um grupo isolado de outras dinâmicas. Olhando de perto para as diferentes maneiras empregadas pelos jovens para usufruir seu tempo livre foi possível entender que os grupos, em constante movimento e não fechados em seus refúgios como tribos urbanas, encontram-se e se conectam, construindo relações. O que fica explícito a partir delas, portanto, é uma experiência não restrita a "espaços guetificados", mas "metropolitana" e "cosmopolita" (:201). Percebe-se que a necessidade de se localizar os atores em suas dinâmicas de sociabilidade está intimamente ligada ao tipo de abordagem de pesquisa. A etnografia é capaz de iluminar relações que à primeira vista se mostram como fluidas, erráticas ou sem sentido, tornando possível a identificação de princípios e ordenamentos sociais em contextos supostamente caóticos. Assim, o acompanhamento atento e participativo do etnógrafo dilui uma aparente desorganização de práticas 
rotineiras, e permite captar as continuidades que organizam, por exemplo, formas de espiritualidade e de diversão.

$\mathrm{Na}$ terceira e última parte do livro, o autor procura responder às questões metodológicas acumuladas nesta longa trajetória de experiências etnográficas. Especificamente nos dois primeiros capítulos, retoma e aprofunda algumas reflexões já esboçadas anteriormente, como, por exemplo, nos artigos, "De perto e de dentro: notas para uma etnografia urbana", publicado em 2002, e "As cidades de Tristes Trópicos" de 1999. Ao revisitar algumas abordagens contemporâneas que refletem sobre a cidade, argumenta que frequentemente ela é entendida como um cenário caótico - seja em termos semiológicos, ou no sentido de um local desestruturado e desordenado em decorrência dos processos de urbanização e do avanço do capitalismo. Nesta visão, os atores sociais aparecem somente como excluídos ou atomizados, desconectados de tudo aquilo que os compõem. Contudo, conforme Cardoso e Durham já haviam demonstrado em décadas anteriores, estes agentes devem ser compreendidos positivamente, por aquilo que realmente fazem e constroem e não pelo que supostamente lhes faltaria. Por isso, 0 pesquisador não pode perder de vista que a tarefa de composição da realidade é algo levado a cabo pelos próprios agentes.

É por meio da etnografia que o antropólogo experimenta este desafio. Magnani lembra-nos que o método etnográfico não pode ser entendido enquanto uma mera técnica de pesquisa, pois se constitui como um complexo modo de produção de conhecimento no qual dois "arranjos", um nativo e outro do pesquisador, transformam-se em um terceiro (:266). O etnógrafo, argumenta o autor, deve perceber os cruzamentos entre paisagens e atores, fugindo de oposições entre a estrutura da cidade e os indivíduos que nela moram e circulam. Neste sentido, deve-se buscar uma harmonia entre abordagens micro e macroscópicas: ajustar o foco e os ângulos de análise, intercalando olhares de fora e de longe com outros de perto e de dentro (:278). No final do livro, o autor propõe uma nova forma de se pensar a aparente oposição entre se fazer pesquisa na cidade ou da cidade. Magnani defende que estes polos de análise sejam entendidos em sua complementaridade. $O$ antropólogo pode ampliar sua perspectiva analítica na medida em que estabelece "estratégias que articulem diferentes perguntas e quadros de análise, buscando uma mais ampla compreensão desse multifacetado objeto que é a cidade, em suas diferentes formas e escalas" (:312).

Magnani encaminha ao final, então, uma discussão sobre a possibilidade de se extrair, a partir da imensa diversidade de conteúdos e particularidades descritas ao longo de décadas de pesquisas em contextos urbanos, princípios que pudessem nos levar a alguma generalização. Recorrendo a alguns apontamentos de Lévi-Strauss em Tristes Trópicos, questiona, então, se o método etnográfico não possibilitaria uma antropologia capaz de perceber escalas universais das cidades. Uma das saídas conceituais é pensar no que Magnani chama de forma-cidade, em contraposição a outras duas formas de tipos-ideais como acampamento e aldeia (:314) - estas últimas definidas por relações de parentesco, vizinhança e coleguismo. Para o autor, apesar de a forma-cidade ser uma experiência relativamente recente, poderíamos procurar, contrastando com as outras formas de agrupamento humano, por certos elementos formais já decantados das infinitesimais práticas urbanas. Assim, mais do que aumentar indefinidamente os estudos de caso, limitando a antropologia urbana a uma antropologia na cidade, anuncia-se o 
momento de consolidar teorias e generalizações. Se esta proposta pode nos parecer ambiciosa, o próprio autor ressalva que estes desdobramentos constituem uma "agenda para mais adiante" (:321).

Por fim, cabe-nos ressaltar que, ao mesmo tempo em que se revela um importante documento sobre a constituição do campo da Antropologia Urbana brasileira, este livro de José Guilherme Magnani discute com profundidade as particularidades teóricas e metodológicas decorrentes das questões abertas por este novo projeto teórico, tornando-se desde já uma referência para quem planeja ou já realiza incursões etnográficas na cidade. 